
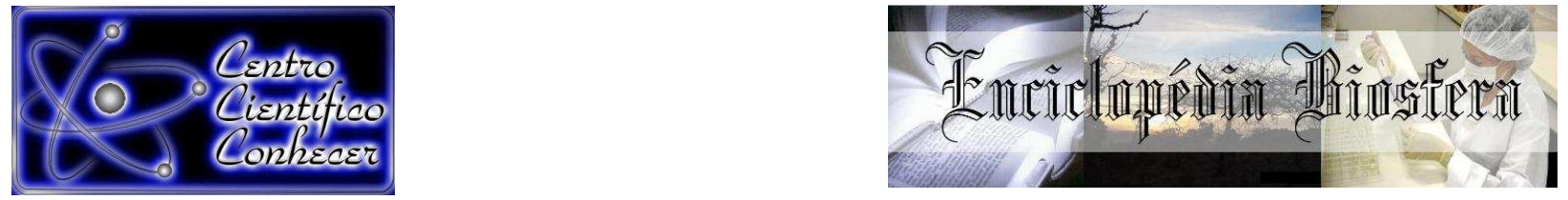

\title{
ANÁLISE DA QUALIDADE DA ÁGUA PARA CONSUMO HUMANO EM INSTITUIÇÕES DE ENSINO ABASTECIDAS PELA ETA MIRINGUAVA
}

\author{
Geovana Lopes Pereira1', Janaina Maria Woinarovicz'1, Jhenifer Da Silva \\ Cornelsen ${ }^{1}$, Cássia Beatriz Lazzarottoํ, Jaçanan Eloisa de Freitas Milani² \\ 1 Discente do Curso de Tecnologia em Gestão Ambiental, Faculdade Bagozzi \\ (geovana.pereira@sjp.pr.gov.br) Curitiba-Paraná \\ 2 Docente do Curso de Tecnologia em Gestão Ambiental, Faculdade Bagozzi
}

\section{Recebido em: 03/10/2016 - Aprovado em: 21/11/2016 - Publicado em: 05/12/2016} DOI: 10.18677/EnciBio_2016B_149

Em virtude da evolução populacional, torna-se mais que necessário tratar a água utilizada para consumo humano, recomenda-se o tratamento da mesma para a remoção de organismos, materiais físico-químico e microbiológico, com o propósito de evitar a proliferação de diversas doenças de vinculação hídrica. É indispensável inteirar-se sobre a água destinada ao consumo humano e seus enquadramentos na legislação vigente. $O$ presente trabalho tem por objetivo analisar a qualidade da água em escolas abastecidas pela Estação de Tratamento de Água do Miringuava, administrada pela Companhia de Saneamento Básico do Paraná (SANEPAR), visando identificar possíveis alterações na água consumida por 3.600 alunos de três instituições de ensino público, da cidade de São José dos Pinhais, Paraná. Foram coletadas 13 amostras para análises físico-químicas e microbiológicas, utilizando como ponto de amostragem os reservatórios prediais de armazenamento de água para consumo imediato e o primeiro ponto pós-hidrômetro. Os valores obtidos das análises foram comparados aos padrões de potabilidade exigido pela Portaria 2.914/2011do Ministério da Saúde, e aos resultados fornecidos pela SANEPAR. Dos resultados analisados, 92,31\% apresentaram valores dentro dos padrões de potabilidade e $7,69 \%$ apresentaram turbidez no ponto pós-hidrômetro acima do aceitável para o abastecimento público. Concluiu-se que é necessária a manutenção dos reservatórios prediais periodicamente, assim como 0 monitoramento da qualidade da água pelo órgão público a fim de garantir o direito do cidadão.

PALAVRAS-CHAVE: Abastecimento público, Monitoramento da água, Padrões de Potabilidade.

\section{ANALYSIS OF WATER QUALITY FOR HUMAN CONSUMPTION IN SUPPLIED EDUCATION INSTITUTIONS BY ETA MIRINGUAVA}

\begin{abstract}
Because of population change, it becomes more necessary to treat the water used for human consumption, it is recommended to treat the same for removing ENCICLOPÉDIA BIOSFERA, Centro Científico Conhecer - Goiânia, v.13 n.24; p.1623 2016
\end{abstract}


organisms, physicochemical and microbiological materials in order to prevent proliferation of various diseases of water binding. It is essential to learn up on water intended for human consumption and their frames by law. This study aims to analyze the quality of water supplied schools by Miringuava Water Treatment Plant, managed by Basic Paraná Sanitation Company (Sanepar), to identify possible changes in water consumed by 3,600 students three educational institutions public, the city of São José dos Pinhais, Paraná. We collected 13 samples for physical, chemical and microbiological analyzes, using as a sampling point the gross reservoir water storage for immediate consumption and the first post-meter point. The values obtained from the analysis were compared to the potability standards required by Decree 2,914 / 2011 of the Ministry of Health, and the results provided by SANEPAR. The results analyzed, $92.31 \%$ had values within the potability standards and $7.69 \%$ turbidity present in the post-meter point above the acceptable to the public supply. It was concluded that maintaining the gross reservoir is needed periodically, as well as monitoring water quality by the public agency to ensure the rights of citizens.

KEYWORDS: Public supply, monitoring of water potability standards.

\section{INTRODUÇÃO}

A água é fundamental para vida, sendo um recurso natural indispensável a todo ser vivo, além de ser suporte primordial aos ecossistemas, é utilizada para o consumo humano e atividades socioeconômicas (REBOUÇAS, 2015). A Constituição Federal Brasileira de 1988 assegura através da Política Nacional dos Recursos Hídricos, a disponibilidade de água a toda população, devendo estar dentro dos padrões de qualidade adequados aos múltiplos usos. De acordo com LEITE et al., (2003), no Brasil "morrem 29 pessoas ao dia por doenças decorrentes da qualidade da água e do não tratamento de esgotos." Também se estima que "cerca de $70 \%$ dos leitos dos hospitais estejam ocupados por pessoas que contraíram doenças de veiculação hídrica."

O Ministério da Saúde através da Portaria no 2.914/2011 dispõe sobre os procedimentos de controle e vigilância da qualidade da água, a fim de garantir que a mesma seja tratada, limpa, potável, e livre de contaminações microbiológica, química, física ou radioativa, não podendo de nenhuma maneira trazer riscos à saúde humana. O tratamento tem por finalidade melhorar a qualidade da água de abastecimento ao público, este procedimento constitui na adequação da água bruta (BRASIL, 2011). Genericamente o tratamento de água ocorre pela remoção de partículas suspensas e coloidais, matéria orgânica, micro-organismos e outras substâncias insalubres para a saúde da sociedade (DI BERNARDO et al., 2011).

As águas tratadas ainda podem apresentar índices de contaminação microbiológica devido às redes internas de fornecimento, ou seja, cisterna, caixas d'água, torneiras e bebedouros; caso a manutenção e limpeza não venham a ser realizada corretamente (DE LIMA, 2012). Sendo assim, a proteção se torna o melhor método de assegurar a água adequada para o consumo humano, através da realização da limpeza e desinfecção dos reservatórios prediais, regular e periodicamente. A falta de limpeza nos ENCICLOPÉDIA BIOSFERA, Centro Científico Conhecer - Goiânia, v.13 n.24; p.1624 
reservatórios prediais expõe a comunidade, à ingestão de água contaminada por agentes biológicos, que se torna um agravante à saúde humana (BIER \& FERNANDES, 2013).

Devido às precárias condições de saneamento básico e a falta de manutenção dos reservatórios prediais, as doenças de vinculação hídrica como: febre tifoide, cólera, amebíase, giardíase, hepatite infecciosa, verminoses, têm sido responsáveis por diversos surtos epidêmicos e pelas elevadas taxas de mortalidade infantil, relacionadas à água de consumo humano (SILVA et al., 2013).

Dessa forma, o presente artigo tem por objetivo verificar a qualidade físico-química e bacteriológica da água utilizada por alunos de três instituições de ensino da rede pública em São José dos Pinhais - Paraná, a considerar que, crianças compõem o grupo de maior risco de contaminação por doenças de vinculação hídrica.

\section{MATERIAL E MÉTODOS}

\section{Área de estudo}

A Cidade de São José dos Pinhais situa-se no Primeiro Planalto Paranaense, com altitude média é de 906 metros, ao Leste do Estado do Paraná, é a $5^{\text {a }}$ maior e uma das mais antigas cidades da Região Metropolitana de Curitiba. Possui uma grandiosa hidrografia, incluindo dois mananciais de abastecimento público: os rios Itaqui e Pequeno. Dispõe de uma área de 948,52 $\mathrm{km}^{2}$, latitude $25^{\circ} 32^{\prime}$ 05" S e longitude $49^{\circ} 12^{\prime} 23^{\prime \prime}$ W (PREFEITURA MUNICIPAL DE SÃO JOSÉ DOS PINHAIS, 2016).Segundo IBGE, através do Censo 2010, São José dos Pinhais tem uma população de 264.210 habitantes, com projeção para 398.607 hab. em 2020. Possui o 2ํㅡㄹ maior PIB do Estado do Paraná e o 36으 do Brasil (Ano de 2012). Seu Índice de Desenvolvimento Humano (IDH) municipal está situado na faixa de Desenvolvimento Humano Alto $(0,758)$ e ocupa a $400^{a}$ posição em relação aos 5.565 municípios do Brasil e $21^{2}$ em relação aos 399 municípios do Paraná.

\section{Área da bacia do rio Miringuava}

A Bacia Hidrográfica do rio Miringuava, área de estudo do projeto, possui uma área de $161,30 \mathrm{~km}^{2}$, aproximadamente $17 \%$ da área total do Município de São José dos Pinhais (PREFEITURA MUNICIPAL DE SÃO JOSÉ DOS PINHAIS, 2016).

A bacia hidrográfica do rio Miringuava localiza-se ao sul da cidade de Curitiba, tem uma área total de $303 \mathrm{~km} 2$, capaz de produzir $898 \mathrm{~L} / \mathrm{s}$, com projeção para $1.600 \mathrm{~L} / \mathrm{s}$ após a futura construção da barragem com uma área de $71,9 \mathrm{~km}^{2}$. A bacia incremental entre a barragem e a captação será da ordem de $40 \mathrm{~km}^{2}$, totalizando uma área útil de $101.9 \mathrm{~km}^{2}$. Atualmente a cabeceira da bacia apresenta boas condições de preservação, com pressão para desmatamentos gerada pela agricultura da região. A maior expressão agrícola sofrida pela bacia é da Colônia Muricy, localizada entre a captação e a barragem, na qual desenvolve agricultura convencional com o uso intensivo de agrotóxicos. Abaixo do ponto de captação previsto, à jusante, 
verifica-se grande ocupação por loteamentos, influência da própria expansão urbana de São José dos Pinhais e várias indústrias de grande porte (SANEPAR, 2016).

\section{Métodos}

A execução desta pesquisa ocorreu entre os meses de abril a junho do ano de 2016. Uma análise preliminar para identificar a Bacia Hidrográfica foi realizada. Na sequência foram delimitadas as três instituições de ensino público escolar, onde foram coletadas 13 amostras de água para serem encaminhadas as análises físico-químicas e microbiológicas. Os pontos definidos de amostragem foram os hidrômetros (pós tratamento público) e os bebedouros (pós reservatórios prediais), com o intuito de avaliar se a qualidade da água distribuída pela SANEPAR está de acordo com os padrões estabelecidos pela Portaria do Ministério da Saúde no 2.914/2011 e se não há alterações na qualidade da mesma durante o trajeto da ETA até as instituições, no caso pós hidrômetro. Considerou-se também a manutenção e limpeza dos reservatórios prediais que, não realizadas, podem alterar as características da água.

Desenvolveu-se um checklist para ser utilizado mediante as coletas das amostras, com a finalidade de obter informações que constam na tabela 1. As instituições têm características distintas de infraestrutura e público, juntas atendem 3.600 alunos diariamente.

Na tabela 1, observa-se a distância das instituições de ensino da Estação de Tratamento de Água do Miringuava, afim de analisar os pontos e suas respectivas distancias. Também se identifica o tamanho dos reservatórios prediais que cada instituição possui e o número de pessoas atendidas por dia que, foram itens indispensáveis para os resultados obtidos. A data da última limpeza e/ou manutenção dos reservatórios prediais também foram considerados.

TABELA 1. Características das instituições de ensino.

\begin{tabular}{l|c|c|c|c}
\hline $\begin{array}{l}\text { UNIDADES DE } \\
\text { AMOSTRAGEM }\end{array}$ & $\begin{array}{c}\text { DISTÂNCIA ATÉ } \\
\text { ESTAÇÃO DE } \\
\text { TRATAMENTO } \\
\text { DO MIRINGUAVA }\end{array}$ & $\begin{array}{c}\text { TAMANHO DOS } \\
\text { RESERVATÓRIOS } \\
\text { PREDIAIS }\end{array}$ & $\begin{array}{c}\text { NÚMERO DE } \\
\text { PESSOAS } \\
\text { ATENDIDAS/ } \\
\text { DIA }\end{array}$ & $\begin{array}{c}\text { PERIODO DE } \\
\text { MANUTENÇÃO } \\
\text { DOS } \\
\text { RESERVATÓRIOS }\end{array}$ \\
\hline $\begin{array}{l}\text { Ponto 01: CMEI - } \\
\text { João de Barro } \\
\text { Preto }\end{array}$ & $\begin{array}{c}500 \text { metros de } \\
\text { distância }\end{array}$ & 03 mil litros & 100 & Outubro $/ 15$ \\
\hline $\begin{array}{l}\text { Ponto 02: } \\
\text { Colégio Estadual } \\
\text { Unidade Polo }\end{array}$ & $5,6 \mathrm{~km}$ de distância & 08 mil litros & 1.400 & Há 6 meses \\
\hline $\begin{array}{l}\text { Ponto 03: } \\
\text { Colégio Estadual } \\
\text { Costa Viana }\end{array}$ & $6,9 \mathrm{~km}$ de distância & $\begin{array}{c}\text { 02 mil litros } \\
\text { (somente para } \\
\text { bebedouros) }\end{array}$ & 2.100 & Fevereiro/16 \\
\hline
\end{tabular}

As amostras colhidas nos pontos determinados também foram préavaliadas in loco, neste foram realizadas análises para identificar os parâmetros de cloro residual e pH (potencial hidrogeniônico), segundo metodologia proposta na portaria M.S. no 2914/2011). O equipamento utilizado nas análises de Cloro e pH foi o kit test chlorine \& ph pocket colorimeter II, o método utilizado ENCICLOPÉDIA BIOSFERA, Centro Científico Conhecer - Goiânia, v.13 n.24; p.1626 
foi Cloro total, Ultra-High Range $(0,0-10,0 \mathrm{mg} / \mathrm{L} \mathrm{Cl} 2)$, utilizado para a água de relatórios e análises de águas residuais, para testar níveis mais elevados de cloro total (livre e combinado) na água potável, água de arrefecimento, águas de processos industriais, ou águas residuais tratadas, e para $\mathrm{pH}$ o método utilizado foi o hach - vermelho de fenol com alcance de 6,0 a 8,5 pH.

Foram encaminhadas as amostras para análises em um Laboratório, com a finalidade de serem examinados os parâmetros físico-químicos e microbiológicos. As técnicas adotadas atendem a Portaria do Ministério da Saúde $n^{\circ} 2.914 / 2011$, a fim de quantificar os coliformes e heterótrofos nas águas coletadas, visando atender as especificações do Standard Methods for the Examination of Water and Wastewater, publicação da American Public Health Association (APHA), American Water Works Association (AWWA) e Water Environment Federation (WEF), estipuladas pela legislação em questão.

Os resultados obtidos foram confrontados entre valores resultantes dos hidrômetros e dos bebedouros, alinhando com os resultados fornecidos pela SANEPAR (via site da Companhia). A finalidade foi identificar se havia possibilidades de contaminações no caminho em que a água percorre nas tubulações até chegar aos consumidores finais, ressaltando que todas as análises foram averiguadas conforme os padrões estabelecidos pela Portaria M.S. $n=2.914 / 11$.

\section{RESULTADOS E DISCUSSÕES}

As três instituições estudadas são abastecidas por água tratada sem utilização de filtros pós-hidrômetro, confirmado através dos resultados do checklist aplicado. Equiparando aos resultados encontrados por PIRAGINE KO (2005) em pesquisa realizada com 40 escolas da cidade de Curitiba, constatouse que $97,5 \%$ são atendidas pelo abastecimento público e destas apenas $75 \%$ realizam a manutenção periódica dos reservatórios de água.

Os resultados oriundos das amostras para coliformes totais e Escherichia coli apresentaram-se satisfatórios, retratando a ausência destes critérios nas amostras. O mesmo resultado foi encontrado por SILVA et al., (2009) que analisaram a qualidade da água de três bairros do município de Vitória ES, corroborando com os resultados obtidos. Observam-se na tabela 2, os resultados obtidos para o parâmetro microbiológico para coliformes totais.

TABELA 2. Parâmetro microbiológico para coliformes totais.

\begin{tabular}{l|c|c|c|c}
\hline $\begin{array}{c}\text { UNIDADES DE } \\
\text { AMOSTRAGEM }\end{array}$ & $\begin{array}{c}\text { AMOSTRAGEM } \\
\text { 01 } \\
\text { HIDROMETRO }\end{array}$ & $\begin{array}{c}\text { AMOSTRAGEM 02 } \\
\text { BEBEDOUROS }\end{array}$ & SANEPAR* & $\begin{array}{c}\text { PORTARIA FEDERAL } \\
\text { No 2.914/11** }^{*}\end{array}$ \\
\hline Ponto 01' & Ausência & Ausência & Ausência & Ausência \\
& $100 \mathrm{~mL}$ & $100 \mathrm{~mL}$ & $100 \mathrm{~mL}$ & $100 \mathrm{~mL}$ \\
\hline Ponto 021 & Ausência & Ausência & Ausência & Ausência \\
& $100 \mathrm{~mL}$ & $100 \mathrm{~mL}$ & $100 \mathrm{~mL}$ & $100 \mathrm{~mL}$ \\
\hline Ponto 031 & Ausência & Ausência & Ausência & Ausência \\
& $100 \mathrm{~mL}$ & $100 \mathrm{~mL}$ & $100 \mathrm{~mL}$ & $100 \mathrm{~mL}$ \\
\hline
\end{tabular}

Fonte: * www.sanepar.com.br, 2016 / **bvsms.saude.gov.br, $2016 /{ }^{1}$ conforme tabela 01 
Para o parâmetro de coliformes totais detectou-se ausência nas três instituições analisadas, pareando com os resultados apresentados pela SANEPAR e enquadrando-se nos padrões de potabilidade exigido pela Portaria M.S. no 2.914/11. Na tabela 3 constatam-se os resultados obtidos no parâmetro microbiológico para Escherichia coli.

TABELA 3. Parâmetro microbiológico para Escherichia coli.

\begin{tabular}{|c|c|c|c|c|}
\hline $\begin{array}{l}\text { UNIDADES DE } \\
\text { AMOSTRAGEM }\end{array}$ & $\begin{array}{l}\text { AMOSTRAGEM } 01 \\
\text { HIDROMETRO }\end{array}$ & $\begin{array}{c}\text { AMOSTRAGEM } 02 \\
\text { BEBEDOUROS }\end{array}$ & SANEPAR ${ }^{\star}$ & $\begin{array}{c}\text { PORTARIA } \\
\text { FEDERAL } \\
\text { № } 2.914 / 11^{\star *}\end{array}$ \\
\hline Ponto $01^{1}$ & $\begin{array}{c}\text { Ausência } \\
100 \mathrm{~mL}\end{array}$ & $\begin{array}{c}\text { Ausência } \\
100 \mathrm{~mL}\end{array}$ & $\begin{array}{l}\text { Ausência } \\
100 \mathrm{~mL}\end{array}$ & $\begin{array}{c}\text { Ausência } \\
100 \mathrm{~mL}\end{array}$ \\
\hline Ponto $02^{1}$ & $\begin{array}{c}\text { Ausência } \\
100 \mathrm{~mL}\end{array}$ & $\begin{array}{c}\text { Ausência } \\
100 \mathrm{~mL}\end{array}$ & $\begin{array}{c}\text { Ausência } \\
100 \mathrm{~mL}\end{array}$ & $\begin{array}{c}\text { Ausência } \\
100 \text { mL }\end{array}$ \\
\hline Ponto $03^{1}$ & $\begin{array}{c}\text { Ausência } \\
100 \mathrm{~mL}\end{array}$ & $\begin{array}{c}\text { Ausência } \\
100 \mathrm{~mL}\end{array}$ & $\begin{array}{c}\text { Ausência } \\
100 \mathrm{~mL}\end{array}$ & $\begin{array}{c}\text { Ausência } \\
100 \mathrm{~mL}\end{array}$ \\
\hline
\end{tabular}

Fonte: * www.sanepar.com.br, 2016 / **bvsms.saude.gov.br, 2016/ ${ }^{1}$ conforme tabela 01

De acordo com a tabela 3, verifica-se que os resultados das coletas 01 , na unidade consumidora e coletas 02 , nos bebedouros, apresentaram resultados desejáveis, enquadrando-se nos padrões estabelecidos e reforçando os resultados aferidos por GUERRA et al., (2006), com ausência de E. coli em estudos realizados na cidade de Bandeirantes, também no estado do Paraná.

Os resultados encontrados para fluoreto enquadram-se aos padrões de potabilidade, estabelecidos na Portaria M.S. no 635/1975 que estabelece um valor mínimo de $0,6 \mathrm{mg} / \mathrm{L}$, não podendo ultrapassar o valor máximo permitido (VMP) de 1,5 mg/L, considerando o nível ótimo em torno de 1,0 mg/L (BRASIL, 1975), conforme tabela 4.

TABELA 4. Parâmetro físico-químico para fluoreto.

\begin{tabular}{|c|c|c|c|c|}
\hline $\begin{array}{l}\text { UNIDADES DE } \\
\text { AMOSTRAGEM }\end{array}$ & $\begin{array}{l}\text { AMOSTRAGEM } 01 \\
\text { HIDROMETRO }\end{array}$ & $\begin{array}{l}\text { AMOSTRAGEM } \\
02 \\
\text { BEBEDOUROS }\end{array}$ & SANEPAR ${ }^{*}$ & $\begin{array}{c}\text { PORTARIA } \\
\text { FEDERAL } \\
\text { № } 2.914 / 11^{\text {** }}\end{array}$ \\
\hline Ponto $01^{1}$ & 0,7 & 0,6 & 0,7 & $1,5 \mathrm{mg} / \mathrm{L}$ \\
\hline Ponto $02^{1}$ & 0,7 & 0,7 & 0,7 & $1,5 \mathrm{mg} / \mathrm{L}$ \\
\hline Ponto $\mathbf{0 3}^{1}$ & 0,8 & 0,6 & 0,7 & $1,5 \mathrm{mg} / \mathrm{L}$ \\
\hline
\end{tabular}

Fonte: * www.sanepar.com.br, 2016 / **bvsms.saude.gov.br, 2016/ ${ }^{1}$ conforme tabela 01

Em relação ao $\mathrm{pH}$ todas as amostras atenderam aos padrões. Os resultados encontrados, corroborando com os estudos de CAMPOS et al. (2003) que, em pesquisas sobre o saneamento no município de Atibaia SP, concluíram que todas as amostras coletadas da rede de abastecimento público atenderam a legislação, estando de acordo com a Portaria M.S. no 2.914/11, que recomenda $\mathrm{pH}$ na faixa de 6,0 a 9,5. Na tabela 5, notam-se os resultados. 
TABELA 5. Parâmetro físico-químico para pH.

\begin{tabular}{l|c|c|c}
\hline $\begin{array}{c}\text { UNIDADES DE } \\
\text { AMOSTRAGEM }\end{array}$ & $\begin{array}{c}\text { AMOSTRAGEM 01 } \\
\text { HIDROMETRO }\end{array}$ & SANEPAR & $\begin{array}{c}\text { PORTARIA FEDERAL } \\
\text { No 2.914/11 }^{\star \star}\end{array}$ \\
\hline Ponto 01 & 6,9 & 6,5 & 6,0 a 9,5 \\
\hline Ponto 02 & & & 6,0 a 9,5 \\
\hline Ponto 031 & 7,1 & 6,5 & 6,0 a 9,5 \\
\hline
\end{tabular}

Fonte: * www.sanepar.com.br, 2016 / **bvsms.saude.gov.br, 2016/ ${ }^{1}$ conforme tabela 01

Os parâmetros de cloro residual, analisados in loco, também foram satisfatórios, considerando os limites estabelecidos pela Portaria em questão, que determina Cloro Residual entre 0,2 a $5,0 \mathrm{mg} / \mathrm{L}$. Os resultados obtidos validam os encontrados por CAMPOS et al., (2003) que,obtiveram 92\% de análises para cloro residual atendendo aos padrões de potabilidade, sendo todos coletados na rede de abastecimento público. Os resultados podem ser verificados na tabela 6. Segundo QUEIROGA \& VIEIRA (2007) a presença de cloro residual livre na água assegura a qualidade bacteriológica.

TABELA 6. Parâmetro cloro residual.

\begin{tabular}{l|c|c|c}
\hline $\begin{array}{c}\text { UNIDADES DE } \\
\text { AMOSTRAGEM }\end{array}$ & $\begin{array}{c}\text { AMOSTRAGEM 01 } \\
\text { HIDROMETRO }\end{array}$ & SANEPAR & $\begin{array}{c}\text { PORTARIA FEDERAL } \\
\text { No 2.914/11* }^{\star *}\end{array}$ \\
\hline Ponto 011 & 2,0 & 1,2 & 0,2 a 5,0 \\
\hline Ponto 02 $^{1}$ & 2,0 & 1,2 & 0,2 a 5,0 \\
\hline Ponto 031 & 2,0 & 1,2 & 0,2 a 5,0 \\
\hline
\end{tabular}

Fonte: * www.sanepar.com.br, $2016 /{ }^{* *}$ bvsms.saude.gov.br, 2016/ ${ }^{1}$ conforme tabela 01

É importante salientar que o cloro é um excelente agente no combate a microrganismos nocivos à saúde. Porém riscos de uma elevação da concentração do cloro e a necessidade de se existir uma barreira sanitária para evitar a propagação de doenças. Efeitos adversos como, vômitos, náuseas e corrosão estomacal (gastrite e úlcera) entre outros podem ocorrer em decorrência da ingestão excessiva de cloro presente na água (BARBOSA, 2013).

No parâmetro turbidez, tabela 7, constatou-se no ponto de amostragem 03, resultado abaixo do padrão exigido pela Portaria M.S. ㄲo 2.914/11 que, confrontando os resultados alcançados por CAMPOS et al. (2003), encontraram todas as amostras dentro dos padrões de potabilidade estabelecidos. Realizouse uma segunda amostra do ponto 3 para atestar o resultado anterior.

Os demais pontos analisados dos hidrômetros estavam dentro dos padrões exigidos da Portaria do M.S. As análises pós-bebedouro reforçam os resultados obtidos por CAMPOS et al. (2003) onde todas as amostras dos reservatórios apresentaram turbidez inferior a 5 NTU (Unidade Nefelométrica de 
Turbidez), divergindo com ANTUNES et al. (2004) que se depararam com $14,4 \%$ das amostras analisadas acima dos limites exigidos pela Portaria MS no 2.914/11. Na tabela 7apresentam-se os valores dos parâmetros físico-químicos para turbidez, podendo ser observado o resultado que não atende aos padrões de potabilidade em negrito.

TABELA 7. Parâmetro físico-químico para turbidez.

\begin{tabular}{|c|c|c|c|c|}
\hline $\begin{array}{l}\text { UNIDADES DE } \\
\text { AMOSTRAGEM }\end{array}$ & $\begin{array}{l}\text { AMOSTRAGEM } \\
01 \text { HIDROMETRO }\end{array}$ & $\begin{array}{l}\text { AMOSTRAGEM } 02 \\
\text { BEBEDOUROS }\end{array}$ & SANEPAR $^{*}$ & $\begin{array}{c}\text { PORTARIA } \\
\text { FEDERAL } \\
\text { № } 2.914 / 11^{\star *}\end{array}$ \\
\hline Ponto $01^{1}$ & $\overline{0,54}$ & $\overline{0,57}$ & 0,35 & $\overline{5,0 \mathrm{NTU}}$ \\
\hline Ponto $02^{1}$ & 0,47 & 0,48 & 0,35 & 5,0 NTU \\
\hline Ponto $\mathbf{0 3}^{1}$ & 5,55 & 0,62 & 0,35 & 5,0 NTU \\
\hline
\end{tabular}

A segunda coleta do ponto 3 foi realizada 15 dias após a primeira, com o interesse de confrontar o resultado obtido anteriormente. $O$ valor encontrado na segunda análise pode ser constatado na tabela 8 , em negrito.

TABELA 8. Parâmetro físico-químico para turbidez (segunda coleta, ponto 03).

\begin{tabular}{|c|c|c|c|c|}
\hline $\begin{array}{l}\text { UNIDADES DE } \\
\text { AMOSTRAGEM }\end{array}$ & $\begin{array}{l}\text { AMOSTRAGEM } 01 \\
\text { HIDROMETRO } \\
\text { PRIMEIRA COLETA }\end{array}$ & $\begin{array}{l}\text { AMOSTRAGEM } 02 \\
\text { HIDROOMETRO } \\
\text { SEGUNDA COLETA }\end{array}$ & SANEPAR $^{*}$ & $\begin{array}{c}\text { PORTARIA } \\
\text { FEDERAL } \\
\text { № 2.914/11** }\end{array}$ \\
\hline Ponto 031 & 5,55 & 0,62 & 0,35 & 5,0 NTU \\
\hline
\end{tabular}

Conforme tabela 8 , a segunda coleta realizada no hidrômetro do ponto 3 apresentou turbidez dentro do valor preconizado pela legislação vigente. De acordo LUíZ et al., (2012) turbidez é apenas um aspecto visual inconveniente, na hipótese de não haver outros fatores que interfiram na qualidade da água. Segundo PADILHA (2011) turbidez é um indicador de sólidos dissolvidos em suspensão ou material em estado coloidal, podendo ser orgânicos ou inorgânicos (areia, argila); embora possa estar muitas vezes ligado com elevação na concentração de ferro.

O controle periódico da manutenção e limpeza dos reservatórios prediais e bebedouros são primordiais, garantindo desta forma a qualidade da água fornecida pela concessionária local a todos os usuários do abastecimento público. A conscientização dos responsáveis das instituições analisadas sobre a limpeza e a conservação dos reservatórios prediais foi fundamental para obtenção dos resultados favoráveis do presente trabalho.

\section{CONCLUSÕES}

Dos resultados obtidos, 92,31\% apresentaram valores dentro dos padrões de potabilidade estabelecidos pela Portaria M.S. 2.914/11 e apenas 7,69\% apresentaram alterações acima do aceitável para o abastecimento 
público. Na amostragem do hidrômetro no ponto 03, o parâmetro de turbidez apresentou valor que excedia o tolerável exigido na legislação, porém na análise dos bebedouros do mesmo ponto, verificou-se que a água atendia aos padrões exigidos pela Portaria em voga. O valor excedido pode justificar-se pelo fato do processo de decantação realizado na estação de tratamento de água, onde os sólidos em suspensão entram em repouso, liberando água em condições apropriadas.

Todos os resultados apresentados pela SANEPAR enquadram-se nos parâmetros recomendados pela Portaria M.S. № 2.914/11. Porém recomendase um monitoramento da qualidade da água mais eficiente pelos órgãos públicos competentes, a fim de garantir o direito do cidadão assegurado na legislação vigente, assim como é de extrema valia a manutenção dos reservatórios prediais periodicamente, com a intenção de garantir a mesma qualidade da água fornecida pela SANEPAR.

\section{REFERÊNCIAS}

ANTUNES, C. A.; CASTRO, M. C. F. M.; GUARDA, V. L. M. Influência da qualidade da água destinada ao consumo humano no estado nutricional de crianças com idades entre 3 e 6 anos, no município de Ouro Preto - MG. Alimentos e Nutrição Araraquara, v. 15, n. 3, p. 221-226, 2004. Disponível em: http://servbib.fcfar.unesp.br/seer/index.php/alimentos/article/viewArticle/80>

BARBOSA, C. M.; MARTINS, L. C. Uma análise físico-química da água no contexto social e científico no município de Nova Cruz/RN. In: IX Congresso de Iniciação Científica do IFRN. 2013.

BIER, A. S.; FERNANDES, V. C.; Sistema de aproveitamento de água pluvial em edifícios-estudo de caso em uma edificação comercial. Revista de Engenharia e Tecnologia, v. 5, n. 1, p.127-134, 2013. Disponível em: <http://revistaret.com.br/ojs-2.2.3/index.php/ret/article/view/135>

BRASIL. Portaria $n^{\circ}$ 635, de 26 de dezembro de 1975. Aprova normas e

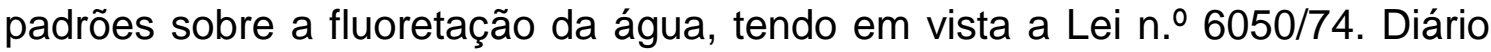
Oficial [da] República Federativa do Brasil, Brasília, DF, 16 de maio de 2016.

BRASIL. Portaria n²914, de 12 de dezembro de 2011.Dispõe sobre os procedimentos de controle e de vigilância da qualidade da água para consumo humano e seu padrão de potabilidade.

CAMPOS, J. A. D. B.; FARACHE FILHO, A.; FARIA, J. B. Uso de reservatórios domiciliares e conhecimento da população. Alimentos e Nutrição Araraquara, v. 14, n.2, p. 171-175, 2003. Disponível em: <http://servbib.fcfar.unesp.br/seer/index.php/alimentos/article/viewArticle/855>

COMPANHIA DE SANEAMENTO DO PARANÁ - SANEPAR - Disponível em <http://www.sanepar.com.br/sanepar/sanare/V12/Mananciais/mananciais.html>. 
Acesso em 02 de maio de 2016.

DE LIMA, N. R.; SCHUROFF, P. A.; PELAYO, J. S.; Qualidade microbiológica da água de abastecimento de centros municipais de educação infantil (CMEI) em Londrina/Paraná no ano de 2012. VIII EPCC - Encontro Internacional de Produção Científica Cesumar, 2013.Disponível em: <http://www.cesumar.br/prppge/pesquisa/epcc2013/oit_mostra/Nicole_Ribeiro_ de_Lima_2.pdf>

DI BERNARDO, L.; DANTAS, A. D. B.; VOLTAN, P. E. N. Tratabilidade de água e dos resíduos gerados em estações de tratamento de água. LDiBE Editora. São Carlos, 2011.

GUERRA, N. M. M., OTENIO, M. H., SILVA, M. E. Z., GUILHERMETTI, M., NAKAMURA, C. V., UEDA-NAKAMURA, T., \& FILHO, B. P. D. Ocorrência de Pseudomonas aeruginosa em água potável. Acta Scientiarum. Biological Sciences, v. 28, n. 1, p. 13-18, 2006.

IBGE - INSTITUTO BRASILEIRO DE GEOGRAFIA E ESTATÍSTICA. Pesquisa Nacional de Saneamento Básico 2008. Rio de Janeiro. Brasil.

LEITE, M. O.; ANDRADE, N. J.; SOUZA, M. R.; FONSECA, L. M.; CERQUEIRA, M. M. O. P.; PENNA, C. F. A. M.; Controle de qualidade da água em indústrias de alimentos.Revista Leite \& Derivados, v. 69, p. 38-45, 2003.

LUÍZ, Â. M. E.; PINTO, M. L. C.; DE OLIVEIRA SCHEFFER, E. W.; Parâmetros de cor e turbidez como indicadores de impactos resultantes do uso do solo, na bacia hidrográfica do rio Taquaral, São Mateus do Sul/PR. RAEGA-O Espaço Geográfico em Análise, v. 24, 2012. Disponível em: <http://revistas.ufpr.br/raega/article/viewArticle/26264>

PADILHA, J. D.; CERUTI, F.C.; DE SOUZA VIDAL, C.M.; \& MARTINS, C. H. (2011). Análise da utilização de três diferentes coagulantes na remoção da turbidez de água de manancial de abastecimento. Encontro Internacional de Produção Científica, v. 7, 2011. Disponível em: $<$ http://www.cesumar.br/prppge/pesquisa/epcc2011/anais/diana_janice_padilha 2.pdf>

PIRAGINE, K.O. Aspectos higiênicos sanitários do prepare da merenda escolar na rede estadual de ensino de Curitiba. Dissertação apresentada para obtenção do titulo de metre. Curitiba: Universidade Federal do Paraná; 2005.

PREFEITURA MUNICIPAL DE SÃO JOSÉ DOS PINHAIS - A Cidade Disponível em http://www.sjp.pr.gov.br/a-cidade/, São José dos Pinhais, 2016. 
QUEIROGA, I. V.; SANTOS, C.; CARNEIRO, L. Ocorrência de Coliformes Totais na Presença de Cloro Residual Mínimo no e Distribuição Público de Água Potável da Cidade de Abadia Goiás. New Lab, Goiás, 83 pág. 148 - 154. Maio. 2007.

REBOUÇAS, A.; Uso inteligente da água. São Paulo, 2008. Ebook. Escrituras Editora e Distribuidora de Livros Ltda., 2015.

SILVA FILHO, A. C.; DE MORAIS, R. D.; DA SILVA, J. B.; Doenças de veiculação hídrica: dados epidemiológicos, condições de abastecimento e armazenamento da água em Massaranduba/PB. Revista Geoambiente Online, p. 01-14, n.20, 2013. Disponível em: $<$ http://www.revistas. ufg.br/index.php?journal=geoambiente\&page=article\&op=vi ew\&path\%5B\%5D=26089\&path\%5B\%5D=0>

SILVA, L. M.; SOUZA, E. H., ARREBOLA, T. M.; JESUS, G. A. Ocorrência de um surto de hepatite $A$ em três bairros do município de Vitória (ES) e sua relação com a qualidade da água de consumo humano. Ciência e Saúde coletiva, v.14, n.6, p.2163-2167, 2009. Disponível em: <http://search.proquest.com/openview/a86282db27cc55c9e54e87f5ed3b38b8/1 .pdf?pq-origsite $=$ gscholar\&cbl=2034998> 